
Recebido em 03/08/2018. Aprovado em 21/08/2018. Avaliado pelo sistema cableblindpeer review Publicado conforme normas da ABNT.
http://dx.doi.org/10.22279/navus.2019.v9n3.p20-40.789

Gabriel Marmentini Mestre em Administração. Universidade do Estado de Santa Catarina (UDESC) - Brasil. gabrielmarmentini@gmail.com

Denilson Sell Doutor em Engenharia da Produção. Universidade do Estado de Santa Catarina (UDESC) - Brasil. denilsonsell@gmail.com

\title{
Gestão do conhecimento no terceiro setor: um diagnóstico de três organizaçōes da sociedade civil
}

\begin{abstract}
RESUMO
Considerando o conhecimento como ativo principal para qualquer organização - independente do setor, área de atuação e tamanho - a Gestão do Conhecimento (GC) precisa ser melhor explorada em uma população significativa de organizações, as do terceiro setor, que hoje já representam cerca de 820 mil instituições no país. Este artigo visa avaliar a Gestão do Conhecimento em três organizações da sociedade civil (OSCs) por meio de uma abordagem quantitativa e qualitativa. Objetiva-se avaliar instrumento de análise de maturidade da GC aplicado em larga escala no segundo setor e identificar lacunas e as necessidades específicas do terceiro setor para orientar futuros estudos. Tem-se como hipóteses que o instrumento não é adequado à avaliação do terceiro setor e que as OSCs estudadas não devam alcançar níveis altos de maturidade. Ambas hipóteses foram confirmadas.
\end{abstract}

Palavras-chave: Gestão do Conhecimento. Terceiro setor. Análise de maturidade. Organizações da sociedade civil. Organizações sem fins lucrativos.

\section{Knowledge management in the third sector: a diagnosis of three civil society organizations}

\begin{abstract}
Considering knowledge as the main asset for any organization - regardless of sector, area of activity and size knowledge management needs to be better explored in a significant population of organizations, the third sector, that today represents about 820 thousand institutions in the country. This article aims to evaluate knowledge management in three civil society organizations (CSOs) through a quantitative and qualitative approach. The aim is also to test the instrument chosen in order to identify gaps and the specific needs of the third sector to guide future studies, as this instrument was applied in a large scale in the second sector. It is hypothesized that the instrument does not fully address the needs of the third sector and that the CSOs studied should not reach high levels of maturity. Both hypotheses were confirmed.
\end{abstract}

Keywords: Knowledge management. Third sector. Maturity evaluation. Civil society organizations. Non-profit organizations. 


\section{INTRODUÇÃO}

Assumindo que organizações são sistemas abertos e orgânicos , que se relacionam com muitos atores e interesses ao mesmo tempo, a complexidade é inerente às organizações. A grande dificuldade está em quebrar o velho paradigma de certeza, controle e linearidade e adentrar no paradigma da complexidade.

A representatividade deste setor é indiscutível. De acordo com dados do Ministério do Trabalho, apresentados em um Mapa das OSCS ${ }^{1}$ realizado pelo Instituto de Pesquisa Econômica Aplicada - IPEA, em 2014, o número de OSCs em atividade no país já ultrapassava 391 mil. 0 que muitas vezes era visto como um setor puramente idealista e pouco competente foi se modificando e tomando um corpo institucional a caminho da profissionalização, refutando o mito da incompetência uma vez estabelecido (SALAMON: ANHEIER, 1997). Ainda assim, as organizações do terceiro setor apresentam uma série de dificuldades em sua gestão, em grande parte das vezes associadas à falta de conhecimento e recursos.

Se a ideia de profissionalismo, inspirando-se no aspecto mercadológico, estivesse acoplada à missão das organizações e à mentalidade de seus agentes, parte dos desafios que aqui serão discutidos poderiam ser menores ou não existirem. 0 que ocorre em muitos casos, por não se identificarem como organizações competitivas como as do segundo setor, é que as boas práticas utilizadas no ramo empresarial e que poderiam ser adaptadas e úteis ao terceiro setor, acabam demorando muito para adentrar na realidade institucional. 0 mesmo ocorre nas instituições públicas, que tendem a não interpretar que "os resultados da gestão, com base em um processo disciplinado de construção e análise de indicadores gerenciais, serão a otimização dos gastos e a maximização do lucro social" (ANDRADE, 2002, p. 16).

Este artigo visa contribuir para minimização dos principais desafios das OSCs mostrando como uma potencial alternativa para aumento de competitividade e eficiência, a gestão do conhecimento. Trata-se de uma prática que está se tornando comum ao ramo empresarial e que pode ter o mesmo impacto no terceiro setor, especialmente, no que envolve mensuração de impacto, uma vez que as organizações têm dificuldade na formulação de indicadores, monitoramento e transparência, e na retenção do conhecimento de voluntários, dada a alta volatilidade da atividade.

Assim sendo, o foco deste artigo está na realização de uma avaliação da gestão do conhecimento em três organizações da sociedade civil. Optou-se pelo uso de uma metodologia já consolidada para avaliação da maturidade da GC aplicada, originalmente destinada a pequenas e médias empresas asiáticas, mas que vem sendo aplicada mundialmente no primeiro e segundo setores.

Parte-se da hipótese de que as organizações estudadas não estarão em níveis altos de maturidade em gestão do conhecimento, tendendo a medianas para baixo. Uma outra hipótese de partida é que 0 instrumento de coleta, embora consolidado na literatura, não será de todo eficaz para as organizações do terceiro setor, constatando-se a necessidade para que futuros estudos utilizem outros métodos já existentes, a fim de testá-los como este foi, ou, até mesmo, que futuras pesquisas se proponham a criar melhores modelos de avaliação focados no terceiro setor. Ademais, espera-se identificar lacunas que possam dar base a futuros estudos que transcendam a questão de análise de maturidade, mas que tratem com mais amplitude o tema da gestão do conhecimento no terceiro setor. Por fim, é importante ressaltar que como há poucas referências nacionais sobre o tema da Gestão do Conhecimento no terceiro setor, este estudo se justifica como mais um passo para aprofundar tais discussões.

Na seção de número do is será melhor explorado os conceitos basilares deste artigo: terceiro setor e Gestão do Conhecimento. Na seção de número três, uma breve caracterização das três OSCs objeto deste estudo. Logo após, foram abordados o método da pesquisa, os resultados, a discussão dos resultados e as conclusões.

${ }^{1}$ Organizações da sociedade civil. 


\section{FUNDAMENTAÇÃO TEÓRICA}

A seguir serão apresentados os conceitos de terceiro setor e gestão do conhecimento, basilares para o presente estudo.

\subsection{Terceiro setor}

As organizações que compõem o chamado terceiro setor são popularmente conhecidas como ONGs ou organizações não governamentais. Juridicamente tal termo não é válido, sendo correto denominarmos as entidades sem fins lucrativos como associações ou fundações, conforme o artigo 44으 do Có digo Civil (BRASIL, 2002). A diferenciação entre ambas está nas entrelinhas do mesmo instrumento legal, do artigo 440 ao 69․ A principal diferença consiste nas condições de constituição, visto que na associação tem-se um processo mais simples, onde os próprios associad os podem se constituir legalmente por meio de uma assembleia, transcrição do estatuto e registro em cartório. No caso das fundações, a constituição não se dá pelo agrupamento de pessoas, mas por um patrimônio específico reconhecido pelo Ministério Público. Nas associações o patrimônio pode existir, mas não se trata de uma condição de existência. Além disso, uma fundação tem finalidades específicas definidas pelo Código Civil, já uma associação tem liberdade para definir a sua. Vale frisar que o termo ONG é apenas um entre tantos que entraram no senso comum. Há outros que não têm um amparo legal (Quadro 1), como o termo ONG, e uma outra parte que, apesar de existir juridicamente, tratam-se de certificações que podem ou não ser concedidas a uma organização do setor (quadro 2).

\begin{tabular}{|c|c|}
\multicolumn{2}{c|}{ Quadro 1 - Termos } \\
\hline Termo & Significado \\
\hline ONG & Organização Não Governamental \\
\hline OSC & Organização da Sociedade Civil \\
\hline Instituto & Nome fantasia de uma associação ou fundação \\
\hline Entidade & Termo genérico \\
\hline Organização & Termo genérico \\
\hline OSFL & Organização Sem Fins Lucrativos \\
\hline Filantrópica & $\begin{array}{c}\text { Entidades portadoras do Cebas que prestam serviços } \\
\text { sociais, comumente nas áreas de saúde, educação e } \\
\text { assistência social }\end{array}$ \\
\hline
\end{tabular}

Fonte: Elaborado com base em Tozzi (2015).

Quadro 2 - Certificações

\begin{tabular}{|c|c|}
\hline Termo & Significado \\
\hline UPF & Utilidade Pública Federal \\
\hline UPE & Utilidade Pública Estadual \\
\hline UPM & Utilidade Pública Municipal \\
\hline OSCIP & Organização da Sociedade Civil de Interesse Público \\
\hline OS & Organização Social \\
\hline Cebas & Certificado de Entidade Beneficente de Assistência Social \\
\hline
\end{tabular}

Fonte: Elaborado com base em Tozzi (2015).

A despeito das diferenças semânticas, no senso comum estamos falando de organizações privadas da sociedade civil, sem fins lucrativos, que têm por objetivo promover e defender uma causa específica. No que envolve a teoria não é tão simples assim. De acordo com Gohn (2001, p. 60, 74): 
o terceiro setor é um tipo de 'Frankenstein': grande, heterogêneo, construído de pedaços, desajeitado, com múltiplas facetas. É contraditório, pois inclui tanto entidades progressistas como conservadoras. Abrange programas e projetos sociais que objetivam tanto a emancipação dos setores populares e a construção de uma sociedade mais justa, igualitária, com justiça social, como programas meramente assistenciais, compensatórios, estruturados segundo ações estratégico-racionais, pautadas pela lógica de mercado. Um ponto em comum: todos falam em nome da cidadania. [...] O novo associativismo do terceiro setor tem estabelecido relações contraditórias com o 'antigo' associativismo advindo dos movimentos sociais populares (na maioria urbanos) dos anos 1970 e 1980.

De forma complementar, Cardoso (1997, p. 13) assinala que:

...é possível que o conceito de Terceiro Setor deva seguir o mesmo percurso histórico que foi trilhado pela noção de Terceiro Mundo. Pode ser que sua diferenciação interna se acentue de tal forma que, no futuro, essa designação já não sirva como conceito unificador e identificador. Hoje, estamos ainda na etapa da afirmação de uma novidade, o que implica enfatizar sua autonomia e relevância.

Além destas reflexões quanto suas contradições, o terceiro setor também apresenta diferentes visões quanto sua composição. De acordo com o Código Civil supracitado, podem ser consideradas como sem fins lucrativos, para além de associações e fundações, as organizações religiosas e os partidos políticos. Já na Constituição Federal de 1988, além dos já citados, tem-se fundações públicas, sindicatos, serviço social autônomo, cultos religiosos, igrejas e cooperativas (BRASIL, 1988). Pensando no terceiro setor como o composto por organizações sem fins lucrativos, teríamos, necessariamente, toda esta gama recém apresentada.

0 fato é que a mais significativa pesquisa na área estatística sobre o setor não considera todas essas personalidades jurídicas. Na última pesquisa "As Fundações Privadas e Associações sem Fins Lucrativos no Brasil - FASFIL", realizada pelo Instituto Brasileiro de Geografia e Estatística - (IBGE, 2010), ficaram de fora boa parte delas, o que culminou em uma pesquisa que considerava apenas fundações e associações privadas e organizações religiosas. Essa foi a terceira edição da pesquisa e a primeira adotando tal postura metodológica, o que reforça o processo de amadurecimento pelo qual ainda estamos passando neste setor. Na seção de conceituação dos resultados da Fasfil, constam os critérios utilizados para tal definição e por não ser objeto deste estudo não haverá um maior aprofundamento. Apenas é necessário frisar que o objetivo principal desta reestruturação metodológica foi de se aproximar da metodologia utilizada internacionalmente, criada pela ONU, em conjunto com a Universidade J ohn Hopkins a fim de poder realizar comparações críveis com estudos anteriores e internacionais (ONU, 2003).

A pesquisa Fasfil reconhece a existência de 556,8 mil organizações sem fins lucrativos, em 2010, no entanto apenas 290,7 mil representam o universo ao qual comumente associamos ao terceiro setor (IBGE, 2010). Corroborando com a ideia de um setor ainda em consolidação, um dos dados da Fasfil, que consiste nas faixas de ano de fundação das organizações, nos mostra que as instituições mais antigas, criadas até 1980, representam apenas $12,7 \%$ do total, ao passo em que $40,8 \%$ das organizações foram criadas no período de 2001 a 2010 (IBGE, 2010).

Quadro 3 - Pessoal ocupado assalariado, segundo as faixas de ano de fundação

\begin{tabular}{|c|c|c|c|c|}
\hline \multirow{2}{*}{$\begin{array}{c}\text { Faixas de ano } \\
\text { de fundação }\end{array}$} & \multicolumn{2}{|c|}{$\begin{array}{c}\text { Fundações Privadas e Associações sem Fins } \\
\text { Lucrativos }\end{array}$} & \multicolumn{2}{c|}{ Pessoal ocupado assalariado } \\
\cline { 2 - 5 } & Total & Percentual (\%) & Total & Percentual (\%) \\
\hline Total & $\mathbf{2 9 0 6 9 2}$ & $\mathbf{1 0 0 , 0}$ & $\mathbf{2 ~ 1 2 8 ~ 0 0 7}$ & $\mathbf{1 0 0 , 0}$ \\
\hline Até 1970 & 9558 & 3,3 & 604951 & 28,4 \\
\hline De 1971 a 1980 & 27270 & 9,4 & 401545 & 18,9 \\
\hline De 1981 a 1990 & 45132 & 15,5 & 306441 & 14,4 \\
\hline
\end{tabular}




\begin{tabular}{|c|c|c|c|c|}
\hline De 1991 a 2000 & 90079 & 31,0 & 419406 & 19,7 \\
\hline De 2001 a 2005 & 58388 & 20,1 & 218690 & 10,3 \\
\hline 2006 & 11869 & 4,1 & 36575 & 1,7 \\
\hline 2007 & 11551 & 4,0 & 33987 & 1,6 \\
\hline 2008 & 11464 & 3,9 & 53840 & 2,5 \\
\hline 2009 & 13726 & 4,7 & 34579 & 1,6 \\
\hline 2010 & 11655 & 4,0 & 17993 & 0,8 \\
\hline
\end{tabular}

Fonte: IBGE (2010, p. 30).

Outro dado que também reforça a relevância do setor é a quantidade de pessoas empregadas, que ficou na casa dos 2,1 milhões em 2010. No entanto, 58,1\% deste número é referente às organizações da região Sudeste, sendo a profissionalização ainda um grande desafio para o setor. Se fosse para aprofundar ainda mais a discussão, a questão da profissionalização ficaria mais complexa, uma vez que temos de observar as organizações por suas atividades fins e seu porte, já que o índice de assalariados tende a variar significativamente. Como exemplo, $72,2 \%$ das organizações identificadas são de pequeno porte e não possuem nenhum empregado formal em seu quadro, evidenciando a importância dos voluntários.

Quadro 4 - Pessoal ocupado assalariado, segundo as faixas de pessoal

\begin{tabular}{|c|c|c|c|c|}
\hline \multirow{2}{*}{$\begin{array}{c}\text { Faixas de pessoal } \\
\text { ocupado assalariado }\end{array}$} & \multicolumn{2}{|c|}{$\begin{array}{c}\text { Fundações Privadas e Associações sem } \\
\text { Fins Lucrativos }\end{array}$} & \multicolumn{2}{c|}{ Pessoal ocupado assalariado } \\
\cline { 2 - 5 } & Total & Percentual (\%) & Total & Percentual (\%) \\
\hline Total & $\mathbf{2 9 0 6 9 2}$ & $\mathbf{1 0 0 , 0}$ & $\mathbf{2 ~ 1 2 8 ~ 0 0 7}$ & $\mathbf{1 0 0 , 0}$ \\
\hline Sem pessoal ocupado & 210019 & 72,2 & - & - \\
\hline De 1 a 2 & 32228 & 11,1 & 43157 & 2,0 \\
\hline De 3 a 4 & 11645 & 4,0 & 39719 & 1,9 \\
\hline De 5 a 9 & 12388 & 4,3 & 82128 & 3,9 \\
\hline De 10 a 49 & 17340 & 6,0 & 376284 & 17,7 \\
\hline De 50 a 99 & 3459 & 1,2 & 239522 & 11,3 \\
\hline De 100 a 499 & 2975 & 1,0 & 601830 & 28,3 \\
\hline 500 e mais & 638 & 0,2 & 745367 & 35,0 \\
\hline
\end{tabular}

Fonte: IBGE $(2010$, p. 50).

O mesmo ocorre no que tange escolaridade e remuneração. Embora a Fasfil tenha identificado que 33\% dos assalariados têm nível superior e que a remuneração média equivale a 3,3 salários mínimos mensais, o que estaria em consonância com os demais salários do país, isso não se aplica ao setor de modo geral. Dependendo dos mesmos fatores levantados anteriormente.

Uma fonte de dados mais atualizada sobre a representatividade das organizações da sociedade civil é o Mapa das OSCs, realizado pelo IPEA e supracitado na introdução deste estudo. Nas imagens abaixo é possível perceber que a representatividade está em uma crescente desde 2010, com leve queda no ano de 2014 e que a soma dos empregos formais por região do país totaliza cerca de 3 milhões de empregos, mais do que o identificado em 2010 na Fasfil. É essa grande parcela de organizações e pessoas que contribuem com $1,4 \%$ da formação do PIB brasileiro, cerca de 32 bilhões de reais (IPEA, 2018). 
Figura 1 - Evolução do número de OSCs ativas

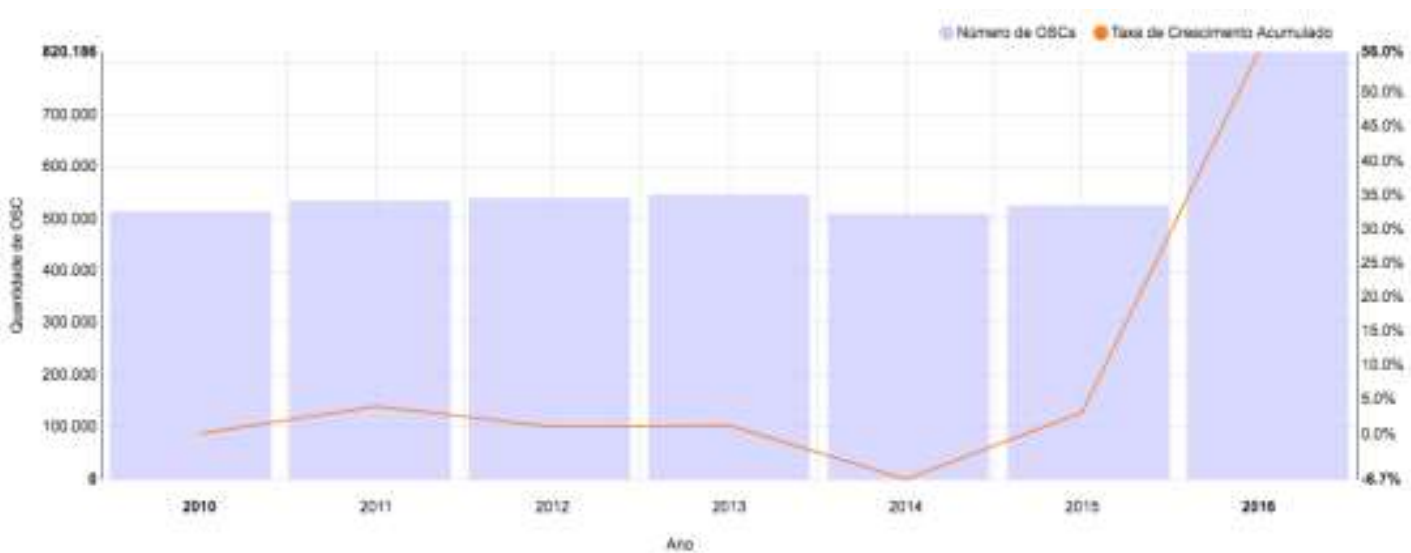

Fonte: IPEA (2018).

Figura 2 - Número de empregos formais nas OSCs por região

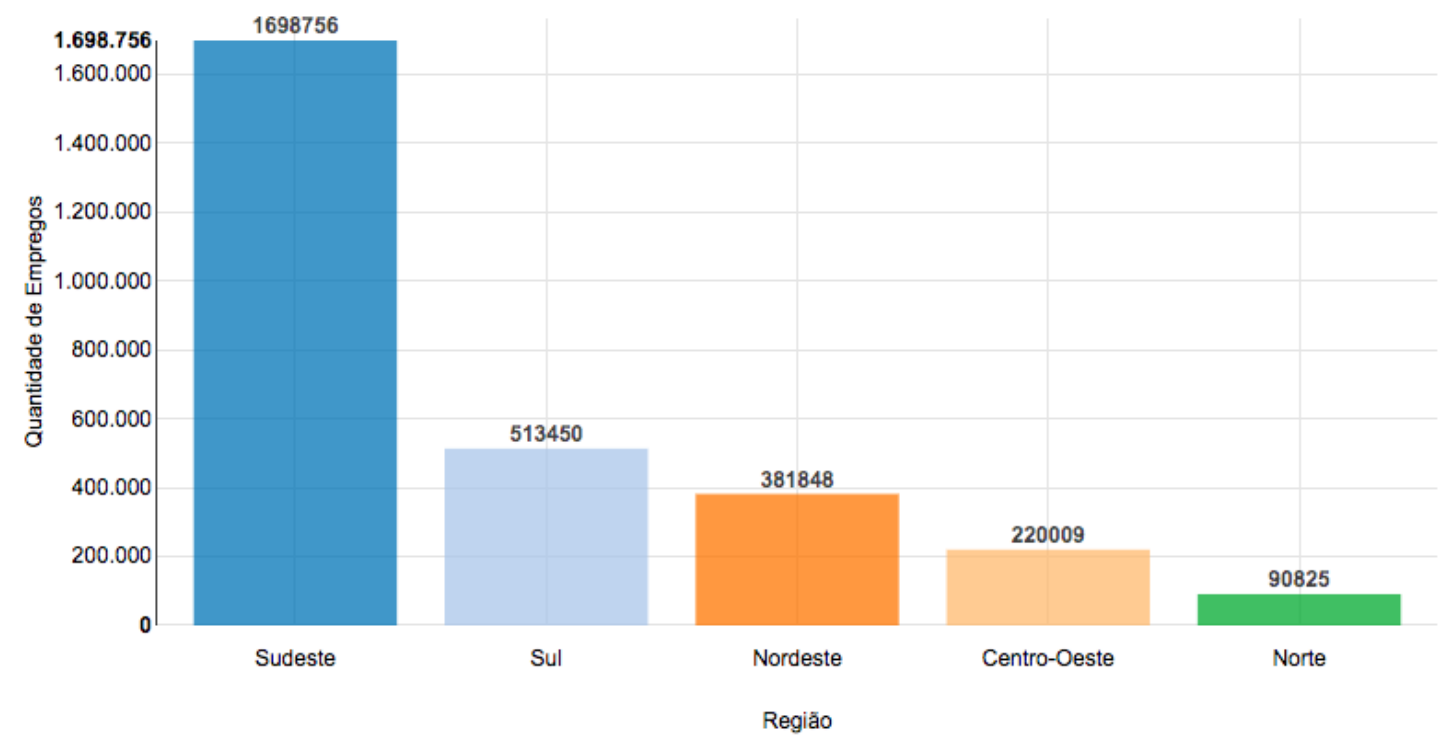

Fonte: IPEA (2018).

É importante citar que o Mapa de OSCs assumiu o mesmo marco teórico da Fasfil e que esta também contou com participação do IPEA, da Associação Brasileira de Organizações Não Governamentais - Abong, do Grupo de Institutos, Fundações e Empresas - GIFE e, pela primeira vez, a Secretaria-Geral da Presidência da República. A partir de toda contextualização apresentada, e considerando a diversidade de visões de um campo, ainda em formação, as seguintes conceituações sobre terceiro setor encerram este aspecto de histórico e representatividade.

Quadro 5 - Conceituações

\begin{tabular}{|l|c|}
\hline \multicolumn{1}{|c|}{ Conceito } & Referência \\
\hline Elas [as organizações] são organizadas, possuem alguma realidade & (SALAMON; \\
institucional. São privadas, separadas institucionalmente do governo. Não & ANHEIER 1997, p. 9) \\
têm fins lucrativos, portanto não retornam lucro aos diretores. São & \\
autônomas e operam suas próprias atividades. São voluntárias, pelo menos \\
em parte, ou seja, envolvem algum grau significativo de participação
\end{tabular}




\begin{tabular}{|l|c|}
\hline $\begin{array}{l}\text { voluntária, seja na condução real das atividades da organização ou na gestão } \\
\text { de seus assuntos }{ }^{2}\end{array}$ & \\
\hline Essas organizações não fazem parte do estado, nem a ele estão vinculadas, \\
mas se revestem de caráter público na medida em que se dedicam a causas e \\
problemas so ciais e em que, apesar de serem de sociedades civis privadas, \\
não tem como objetivo o lucro, e sim o atendimento das necessidades da \\
sociedade.
\end{tabular}

$$
\text { Fonte: Elaborado pelo autor (2018). }
$$

Por vezes foi citado que o setor ainda vive em um processo de amadurecimento. Como em qualquer processo do gênero, desafios são constantes e, muitas vezes, peculiares. Inicialmente, há um problema de legitimidade conceitual e prática, visto que a importância do terceiro setor foi deixada de lado já na essência acadêmica, em que não há enfoque nos estudos sobre o setor (FISCHER; FALCONER, 1998).

A dificuldade em se adequar às conformações jurídicas existentes, os desafios na área de recursos humanos e gestão institucional e a dificuldade em avaliar resultados são exemplos de desafios enfrentados por boa parte das organizações (MADEIRA; BIANCARDI, 2003). Buscar legitimidade perante aos outros setores e a sociedade, ser eficiente na execução dos projetos, ter sustentabilidade no quesito financeiro e buscar parcerias constantes para que, por meio da colaboração, haja formação de alianças estratégias, também são desafios do terceiro setor (SALAMON; ANHEIER, 1997).

Por estes e diversos outros desafios é que se acredita que a Gestão do Conhecimento possa contribuir com o terceiro setor, ainda mais por este possuir um conhecimento ímpar em relação às necessidades específicas de uma comunidade, algo dificilmente alcançado pelo Estado (CAMARGO et al., 2001).

\subsection{Gestão do conhecimento}

Dado, informação e conhecimento. Esses são os três conceitos principais que compõem a lógica da Gestão do Conhecimento. Por dado temos algo primário, que não oferece valor às pessoas por si, não obstante, trata-se de uma raiz do conhecimento. Um conjunto de dados passa a ter valor às pessoas quando é organizado, provendo algum sentido para quem o consome e, neste momento, se transformando em informação. Podemos interpretar o sentido da informação como o valor oferecido ao usuário. Trata-se de algo subjetivo, uma vez que depende totalmente de quem recebe tal informação. Sendo assim, na perspectiva organizacional o valor da informação dependerá do contexto da organização (MORESI, 2000). No entanto, mesmo que não façamos uso de determinadas informações, conseguimos, ao menos, perceber que seriam úteis a alguém, pois, além de estarem organizadas, apresentam características básicas como: precisão, confiabilidade, completude, economicidade, flexibilidade, simplicidade, relevância, entregues em tempo e verificáveis (STAIR, 1998). Combinando os dois primeiros conceitos possibilitamos a existência de conhecimento, que

...é a combinação de dados e informações à qual se adicionam habilidades, experiências e opiniões de especialistas, que resulta em um ativo valioso que pode ser utilizado no apoio à decisão. Conhecimento pode ser explícito e/ou tácito, individual e/ou coletivo (COMITÉ EUROPÉEN DE NORMALISATION, 2004).

\footnotetext{
2 Tradução livre.
} 
Analisando o conceito de conhecimento percebe-se que a discussão vai além dos dados e informações, tem-se no bojo do conhecimento aspectos mais subjetivos, como habilidades e experiências, 0 que nos dá margem para outras definições importantes, como os tipos de conhecimento.

Quadro 6 - Tipos de conhecimento

\begin{tabular}{|l|l|}
\hline \multicolumn{1}{|c|}{ Tácito (subjetivo) } & \multicolumn{1}{c|}{ Explícito (objetivo) } \\
\hline Conhecimento da experiência (corpo) & Conhecimento da racionalidade (mente) \\
Conhecimento simultâneo (aqui e agora) & Conhecimento sequencial (lá e então) \\
Conhecimento análogo (prática) & Conhecimento digital (teoria) \\
\hline
\end{tabular}

Fonte: Elaborado com base em Nonaka e Takeuchi (1997).

Para Polayi (1966 apud NONAKA; TAKEUCHI, 1997, p. 65) "o conhecimento tácito é pessoal, específico ao contexto e, assim, difícil de ser formulado e comunicado. Já o conhecimento explícito ou 'codificado' referese ao conhecimento transmissível em linguagem formal e sistemática".

Ao observarmos a tabela anterior em conjunção com os conceitos de conhecimento, depreende-se que este pode emergir em diversos lugares, estando tanto nas pessoas como em documentos e sistemas, como não somente dentro da organização, mas também nos atores aos quais esta se relaciona, como clientes, fornecedores, parceiros e concorrentes. Contudo, esta visão de mundo não é unívoca na literatura, uma vez que há, no mínimo, três formas distintas de compreender o conhecimento (VENZIN; VON KROGH; ROOS, 1998).

Quadro 7 - Diferentes visões

\begin{tabular}{|c|c|c|}
\hline Visão & Crença & Defensores \\
\hline Cognitivista & $\begin{array}{l}\text { - Foco em identificar, estruturar e } \\
\text { disseminar dados e informações para } \\
\text { desenvolver conhecimento; } \\
\text { O O cognitivismo é associado ao } \\
\text { robótico/máquina, sendo algo universal, } \\
\text { onde todos seguem o mesmo padrão. }\end{array}$ & $\begin{array}{l}\text { Herbert Simon, Noam } \\
\text { Chomsky, Marvin } \\
\text { Minsky, J ohn McCarthy }\end{array}$ \\
\hline Conexisonista & $\begin{array}{l}\text { - É menos universal, considera variações } \\
\text { locais; } \\
\text { - É nas interações que o conhecimento se } \\
\text { desenvolve; } \\
\text { - Foco nas relações, não nos indivíduos; } \\
\text { - Redes que se auto-organizam e são } \\
\text { orientadas à comunicação. }\end{array}$ & $\begin{array}{c}\text { Bruce Kogut e Udo } \\
\text { Zander }\end{array}$ \\
\hline Autopoiética & $\begin{array}{l}\text { - Um inputé um dado. Uma informação é } \\
\text { um dado em um contexto; } \\
\text { - Conhecimento está na mente, no corpo e } \\
\text { nos sistemas sociais; } \\
\text { - O foco está na interpretação da } \\
\text { informação; } \\
\text { É simultaneamente um sistema aberto e } \\
\text { fechado; } \\
\text { - O conhecimento não pode ser transferido } \\
\text { para outra pessoa pois precisa ser } \\
\text { interpretado. }\end{array}$ & $\begin{array}{l}\text { Maturana e Varela, } \\
\text { Nonaka e Takeuchi }\end{array}$ \\
\hline
\end{tabular}

Fonte: Elaborado com base em Venzin, Von Krogh e Roos (1998).

O presente estudo reconhece que não há uma única visão que o deva guiar, visto que parte-se do pressuposto que todas as formas de entender o conhecimento são válidas e, portanto, se complementam. 
Embora seja comum relacionarmos o sucesso de uma organização em função do seu tamanho e lucratividade, é do conhecimento que tudo isso parte, sendo este fator crítico para produção de qualquer atividade de uma organização bem-sucedida. Tratando-se de algo desta importância, é ideal que haja um gerenciamento. Para reforçar ainda mais esta necessidade, faz-se necessário citar que há um custo por não gerirmos as informações e, por conseguinte, o conhecimento. Trata-se de uma simples equação que envolve o custo de oportunidade de não ter a informação necessária e do custo de obtenção, manutenção e utilização de alguma informação. Por outro lado, há também o que se chama de saturação da informação.

Existe uma grande quantidade de informações. A saturação da informação e da pseudoinformação pode gerar problemas, caso se desconheçam os processos adequados de seleção da informação. Devem ser selecionadas, desenvolvidas e aprendidas estratégias de acesso e de seleção de informação. (ZAYAS, 2009, p. 166).

Há um ponto máximo na capacidade de processamento das informações tanto em pessoas quanto em organizações. Portanto, uma maior quantidade de informação não necessariamente implicará em maior uso. Encontrar este equilíbrio é uma tarefa de gestão. É neste contexto da valo rização do conhecimento como um ativo crítico de qualquer organização que emergem os programas de Gestão do Conhecimento.

Por Gestão do Conhecimento temos processos, modelos e práticas que permitem que a organização, de forma estruturada, crie, compartilhe, armazene, distribua e adquira conhecimento. Embora não haja um senso comum na literatura sobre o conceito de Gestão do Conhecimento, abaixo se tem uma amostra de possibilidades.

Quadro 8 - Conceitos de Gestão do Conhecimento

\begin{tabular}{|c|c|}
\hline Conceito & Autor \\
\hline $\begin{array}{l}\text { Abordagem sistemática para encontrar, compreender e usar conhecimento } \\
\text { para criar valor. }\end{array}$ & O'Dell (1996) \\
\hline $\begin{array}{l}\text { Construção sistemática, explícita e deliberada, renovação e aplicação de } \\
\text { conhecimento para maximizar a eficácia do conhecimento de uma empresa e } \\
\text { retornar de seus ativos de conhecimento. }\end{array}$ & Wiig (1986) \\
\hline $\begin{array}{l}\text { Processo de captura de experiência coletiva de uma empresa, onde quer que } \\
\text { resida, e distribuindo para onde quer que seja que possa fornecer melhora na } \\
\text { performance. }\end{array}$ & Hibbard (1997) \\
\hline $\begin{array}{l}\text { Um controle e gestão de conhecimento explícito dentro de uma empresa } \\
\text { visando alcançar os objetivos desta. }\end{array}$ & $\begin{array}{c}\text { Van der Spek e } \\
\text { Spijkervet (1997) }\end{array}$ \\
\hline $\begin{array}{l}\text { Uma estratégia consciente de obter o conhecimento certo para as pessoas } \\
\text { certas no momento certo e que ajude as pessoas a compartilhar e colocar as } \\
\text { informações em prática pensando em maneiras para melhorar o desempenho } \\
\text { organizacional. }\end{array}$ & APQC (1999) \\
\hline $\begin{array}{l}\text { Formalização e acesso à experiência, conhecimento e expertise que criam } \\
\text { novas capacidades, possibilitam um desempenho superior, incentivam a } \\
\text { inovação e melhoram o valor ofertado ao cliente. }\end{array}$ & Buckman (1999) \\
\hline $\begin{array}{l}\text { Gestão sistemática do conhecimento organizacional que envolve os processos } \\
\text { de criação, coleta, organização, armazenamento, difusão, uso e exploração de } \\
\text { conhecimento para a criação de valor comercial e geração de vantagem } \\
\text { competitiva. }\end{array}$ & $\begin{array}{l}\text { Chong e Choi } \\
\text { (2005) }\end{array}$ \\
\hline
\end{tabular}

Fonte: Tradução livre de Choy, Kuan Yew e Lin (2006).

Para facilitar o início das práticas de Gestão do Conhecimento em uma dada organização, a aplicação de escalas para avaliação de maturidade é recomendada como um primeiro passo. Por meio de um diagnóstico inicial é possível perceber em que estágio a organização se encontra e quais são suas forças e fraquezas. Tal avaliação servirá como um marco zero para que os avanços em gestão do conhecimento possam ser melhor compreendidos uma vez que se terá clareza so bre o estágio inicial. Eé justamente com este objetivo de analisar a maturidade de organizações que o presente artigo é desenvolvido. 
Outra expectativa em relação à análise como essa é que, desde o princípio, se crie uma consciência organizacional sobre a importância da mensuração em Gestão do Conhecimento. Eventualmente, os gestores precisam mostrar o valor de um programa de Gestão do Conhecimento. Como o fará sem saber de onde partiu? (VESTAL, 2002).

Estabelecendo uma conexão entre o terceiro setor, a Gestão do Conhecimento e a atual conjuntura política e econômica do país, vemos que o desafio da sustentabilidade financeira para as organizações sem fins lucrativos vem ficando cada vez maior, uma vez que os repasses do governo federal caíram drasticamente e está cada vez mais competitiva a busca por recurso junto ao empresariado.

Figura 3 - Evolução anual dos repasses federais para as OSCs, Brasil - 2009-2017

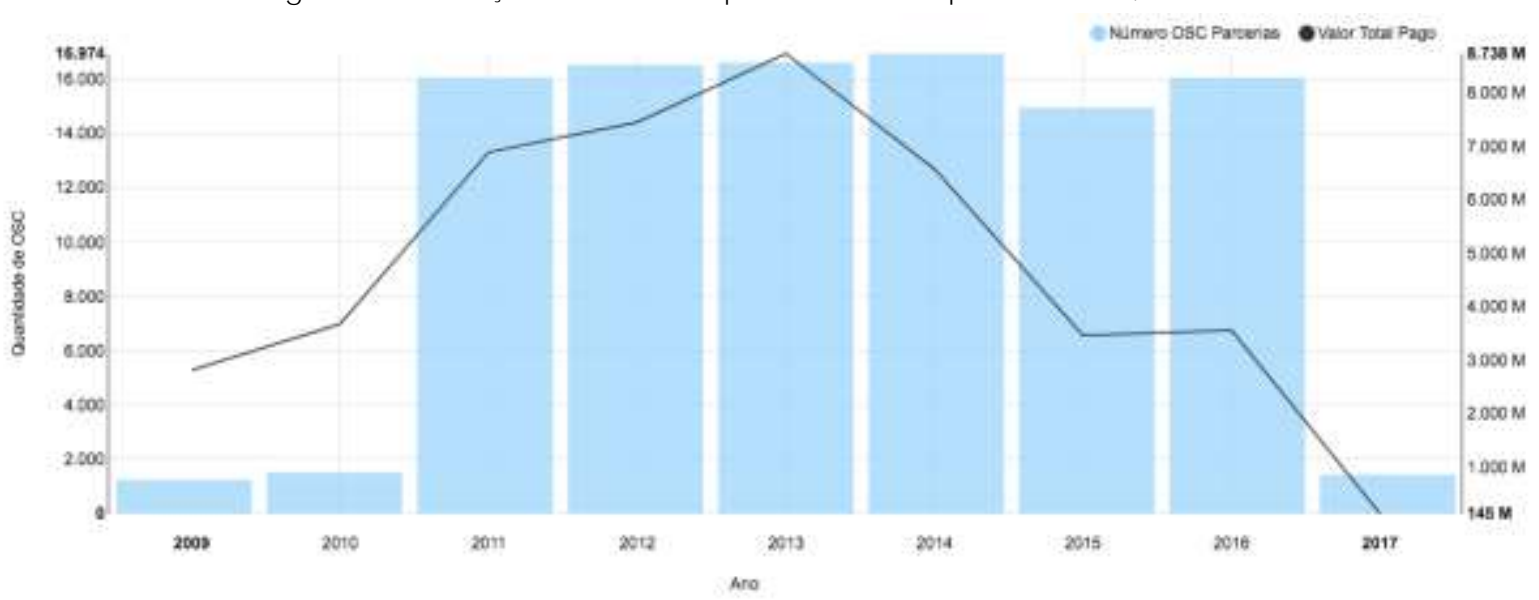

Fonte: IPEA (2017)

A escassez de recursos para o terceiro setor não afeta apenas este ecossistema. Milhares de projetos que geram benefícios para a sociedade deixam de ser executados, bem como há uma tendência em reduzir o número de contratações no setor ou ainda aumentar o número de demissões. Independente da crise econômica, a retração no terceiro setor já havia sido observada na pesquisa Fasfil (IBGE, 2010). No período de 2002 a 2005 houve um crescimento de $22,6 \%$ no setor, mas de 2006 a 2010 este crescimento foi de apenas $8,8 \%$ (IBGE, 2010). O setor continua crescendo, mas em um ritmo menos acelerado. Em um contexto de incertezas, cabem às organizações preservarem seus conhecimentos críticos e alavancarem programas de Gestão do Conhecimento para melhorar a competitividade e otimizar recursos.

\section{CARACTERIZAÇÃO DAS ORGANIZAÇÕES ESTUDADAS}

Nesta seção, objetiva-se descrever cada uma das organizações estudadas com o intuito de contextualizar o leitor antes da análise dos resultados obtidos. 0 questionário adotado na metodologia desta pesquisa foi aplicado em três organizações da sociedade civil (OSCs), todas sediadas em Florianópolis/SC.

É importante reforçar que, embora todas estejam no terceiro setor, cada uma das organizações está inserida em um campo de atuação diferente. Isso ocorreu de forma proposital, visto que parte-se da premissa que os principais desafios de cada organização, não apenas em relação à Gestão do Conhecimento, estão ligados a sua atividade fim, a suas características próprias e pelo contexto no qual estão inseridas. Portanto, temos aqui uma pluralidade de visões e isso foi um dos critérios de escolha das organizações. Outro critério de escolha envolveu a proximidade do pesquisador com as OSCs, dada a abertura para executar a pesquisa.

Por fim, faz-se necessário frisar que o autor convidou outras quatro organizações para participarem do estudo, porém não obteve sucesso. No total, o questionário foi respondido por 19 pesso as, o que representa $100 \%$ dos colaboradores das organizações estudadas até a data da coleta das informações, entre maio e junho de 2017. Para a primeira organização, foram 4 respondentes, para a segunda 7 e para a terceira 8 . A ordem de apresentação das organizações é meramente alfabética e a descrição seguiu um padrão básico que visou 
abordar um breve histórico, o problema social que a organização busca resolver, como busca resolver e as principais conquistas até o momento.

\subsection{Associação de Câncer de Boca e Garganta - ACBG Brasil ${ }^{3}$}

Embora tenha sido fundada em 2015 por um grupo de pacientes e profissionais da saúde de Florianópolis (SC), a ACBG Brasil tem em sua história uma semente plantada anos antes. Foi em 1995 que a fonoaudióloga Elisa Gomes Vieira iniciou um grupo de apoio para pacientes acometidos por câncer de laringe, o que foi chamado de GAL (grupo de apoio a laringectomizados). Com a entrada de novos pacientes em 2011, o grupo ganhou um espírito empreendedor e os envolvidos começaram a se perguntar sobre o que mais poderia ser feito em prol da causa, algo que transcendesse os encontros mensais do grupo.

Apenas em janeiro de 2015 é que a ACBG Brasil foi fundada, tendo por objetivo lutar em prol de direitos e maior qualidade de vida dos pacientes e familiares que enfrentam os desafios dos cânceres de boca e garganta. Os problemas são muitos, mas de acordo com a organização os principais são a defasagem nas políticas públicas focadas nesta área da saúde e a falta de conhecimento desses tipos de cânceres por parte da população e, inclusive, pelo corpo médico de muitas instituições.

Para atender ao problema identificado, a ACBG Brasil trabalha nas frentes de advocacy, reabilitação, inclusão social e disseminação de informação. Desde o início dos trabalhos a ACBG já mobilizou 17 instituições de saúde diferentes em todo o Brasil, impactando diretamente cerca de 100 profissionais da saúde e 200 pacientes. Outro número expressivo são as mais de 1500 pessoas que receberam informações diretas por meio de palestras de conscientização sobre o câncer.

\subsection{Instituto Comunitário Grande Florianópolis - ICOM4}

O ICOM é a organização mais antiga deste estudo. Trata-se de uma fundação comunitária ${ }^{5}$ de Florianópolis que foi fundada em 2005 e em seus 12 anos de atuação conseguiu estabelecer sua identidade como referência no terceiro setor da região.

Apoiar empresas e indivíduos para que possam fazer investimentos sociais e doações com alto impacto social é um dos focos do ICOM. A fundação também auxilia organizações da sociedade civil a terem uma gestão mais eficiente e a servirem como canais de participação dos cidadãos para melhorarem a qualidade de vida na Grande Florianópolis e em Santa Catarina. São três eixos de atuação delimitados pelo ICOM: a) investimentos sociais na comunidade; b) apoio técnico e financeiro às OSCs; c) produção e disseminação de conhecimento. Em sua trajetória o ICOM já atendeu 822 OSCs, impactou 284 mil pessoas e repassou 1,7 milhões de reais em doações.

\subsection{Politize! $!^{6}$}

Se falar de política sempre foi chato e difícil, esta OSC tenta mudar este cenário. Fundada em 2015, 0 Politize! veio como uma alternativa às polarizações e falta de participação cidadã. De acordo com o Economist Inteligence Unit (2017), o Brasil tem uma democracia falha, principalmente pela falta de cultura política e participação política. Foram as manifestações de 2013, que ocorreram em todo o território nacional, que despertaram os empreendedores do Politize! uma vontade de contribuir para que este cenário fosse diferente.

\footnotetext{
${ }^{3}$ Www.acbgbrasil.org

${ }^{4}$ www.icomfloripa.org.br

${ }^{5}$ De acordo com o ICOM, as fundações comunitárias representam mais de 2000 organizações que estão presentes em mais de 50 países. No Brasil há apenas três organizações sob esse conceito: Instituto Rio, fundado em 2001; ICOM, fundado em 2005; Instituto Baixada, fundado em 2009. O ICOM é único no sul do Brasil. Entre as características mais fortes das fundações comunitárias está: atuação com foco territorial, governança representativa na comunidade e ampla base de doadores e investidores.

${ }^{6}$ www.politize.com.br
} 
Em 2014 a primeira rodada de recursos para o projeto veio por meio de uma campanha de captação coletiva e a partir de então a instituição foi fundada e se organizou para entregar o que estava propondo: uma plataforma de conteúdos educativos sobre política e cidadania que fossem fáceis, leves, divertidos e, principalmente, sem vinculações político-partidárias.

Hoje o trabalho do Politize! vem sendo expandido para uma aproximação com escolas e universidades, bem como ampliando seu impacto on-line por meio da produção de cursos à distância em vídeos. Até então mais de 7 milhões de pessoas já utilizaram os conteúdos do portal em todo o Brasil.

\section{MÉTODO}

Os tópicos seguintes versam sobre a metodologia utilizada no presente estudo.

\subsection{Abordagem}

Optou-se por adotar um instrumento já existente de coleta de dados para avaliação de maturidade da Gestão do Conhecimento. 0 instrumento, que será explanado no próximo tópico, consiste em um questionário que, com a compilação das notas conferidas, gera um gráfico de radar que indica fortalezas e fraquezas, bem como, a partir do somatório das notas, indica em que estágio de maturidade a organização está. Tendo em vista que o questionário abre espaço para respostas qualitativas, na linha de pontos fortes e fracos que justifiquem as notas conferidas, a pesquisa teve uma abordagem quantitativa e qualitativa.

\subsection{Instrumento de coleta de dados}

A Organização Asiática de Produtividade7 - APO, criou, em 2009, um instrumento de avaliação da maturidade de organizações no que tange a gestão do conhecimento. 0 questionário apresenta 42 questões que foram divididas em 7 dimensões: liderança, processos da organização, pessoas, tecnologia, processos do conhecimento, inovação e resultados ${ }^{8}$. Para cada dimensão há um espaço aberto para que sejam citados pontos fortes e fracos que justifiquem as notas conferidas. Foi orientado a todos os respondentes que 0 questionário deveria ser preenchido individualmente e com base em sua percepção pessoal e vivência na organização. As notas foram atribuídas respeitando a seguinte lógica:

Quadro 9 - Notas APO

\begin{tabular}{|c|c|}
\hline Descritores & Nota \\
\hline Faz muito bem & 5 \\
\hline Faz bem & 4 \\
\hline Faz & 3 \\
\hline Faz mal & 2 \\
\hline Faz muito mal ou inexistente & 1 \\
\hline
\end{tabular}

Fonte: Tradução livre de ASIAN PRODUCTIVITY ORGANIZATION (2009).

Com o somatório das notas, cada organização foi enquadrada em um dos níveis da escala deste instrumento.

\footnotetext{
${ }^{7}$ Tradução livre para Asian Productivity Organization (APO): http://www.apo-tokyo.org/

${ }^{8}$ Disponível em: http://www.apo-tokyo.org/00e-books/IS-39_APO-KM-FG.htm
} 
Figura 4 - Escala APO

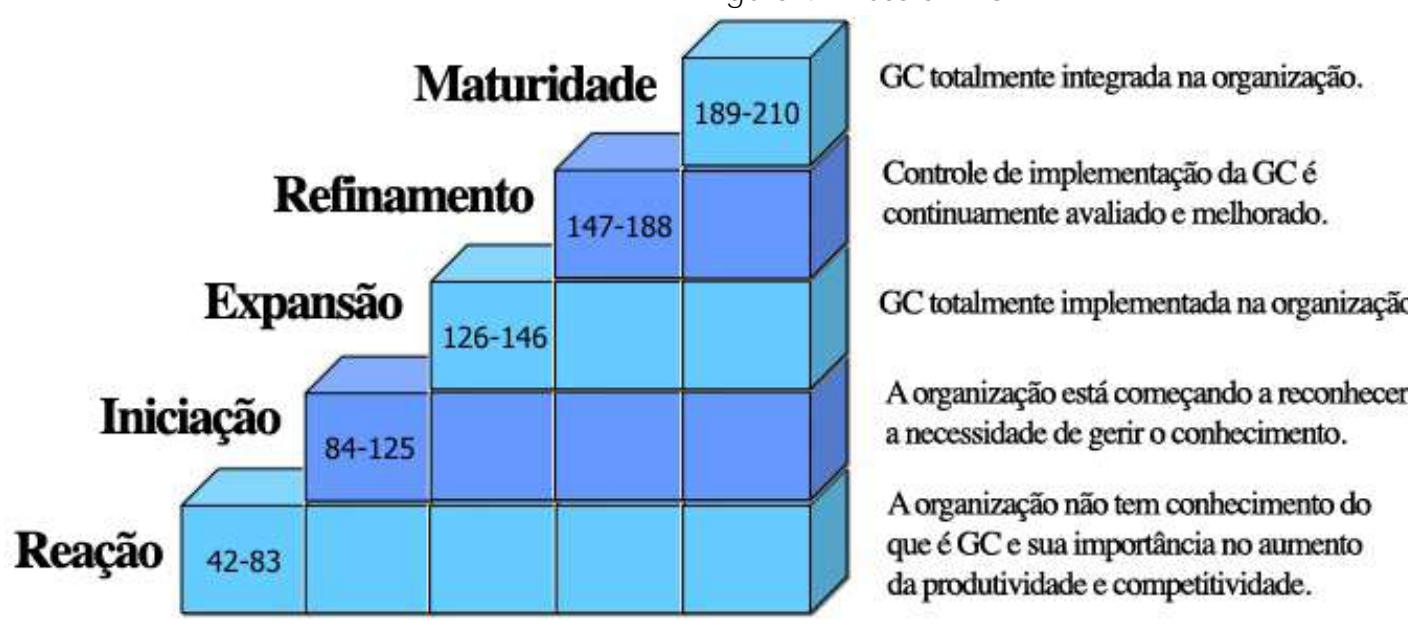

Fonte:Tradução livre de ASIAN PRODUCTIVITY ORGANIZATION (2009).

\subsection{Percurso metodológico}

O percurso metodológico consistiu na definição das organizações que seriam estudadas, explicação da motivação da pesquisa e instruções básicas para participação, aplicação do questionário, compilação e análise dos resultados. Para aplicação do questionário fez-se uso da ferramenta Google Forms e na etapa de compilação fez-se uso de estatística descritiva. As respostas de cada colaborador foram somadas para cada assertiva, chegando em uma média simples do valor geral da assertiva para cada organização. A partir deste número é que se chegou nos gráficos à moda radar.

Figura 5 - Gráfico em radar APO
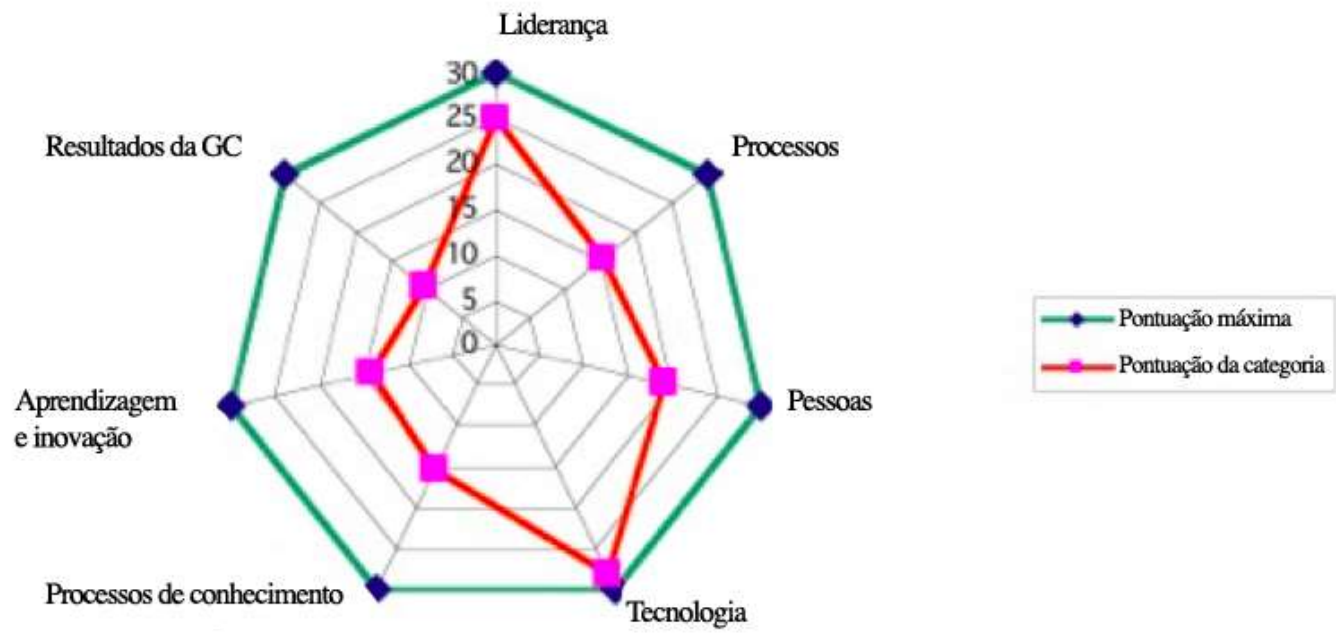

Fonte: Tradução livre de ASIAN PRODUCTIVITY ORGANIZATION (2009).

No momento de análise foi de extrema importância a leitura e interpretação dos depoimentos qualitativos de cada colaborador. Isso possibilitou o destaque para os problemas mais recorrentes, representados na discussão dos resultados. 


\section{RESULTADOS}

Seguindo a mesma ordem de apresentação anterior, esta seção demonstra os resultados alcançados em cada uma das organizações por meio da aplicação do questionário de avaliação da APO. Os resultados serão demonstrados de forma objetiva, uma vez que a discussão dos mesmos está na seção posterior, agregando os aspectos qualitativos da pesquisa. Lembrando que, de acordo com a metodologia adotada, a pontuação máxima para cada dimensão é de 30 pontos, sendo o total máximo de 210 pontos. De acordo com a pontuação, cada organização foi enquadrada em um nível dos cinco possíveis, de acordo com a escala apresentada anteriormente. Ao final apresenta-se uma tabela e um gráfico comparativo.

\subsection{Associação de Câncer de Boca e Garganta - ACBG Brasil}

\section{Quadro 10 - Pontuação da ACBG Brasil}

\begin{tabular}{|l|l|l|}
\hline$\#$ & Dimensão & Pontuação \\
\hline 1 & Liderança & 16,8 \\
\hline 2 & Processos & 19,6 \\
\hline 3 & Pessoas & 18,8 \\
\hline 4 & Tecnologia & 24,6 \\
\hline 5 & Processos de conhecimento & 21 \\
\hline 6 & Aprendizagem e inovação & 25,4 \\
\hline 7 & Resultados da GC & 19 \\
\hline \multicolumn{2}{|l|}{ Total } & $\mathbf{1 4 5 , 2}$ \\
\hline \multicolumn{2}{|l|}{ Terceiro nível identificado: expansão (126-146). } \\
\hline
\end{tabular}

Fonte: Elaborado pelo autor (2018).

\section{Figura 6 - Gráfico da ACBG Brasil}

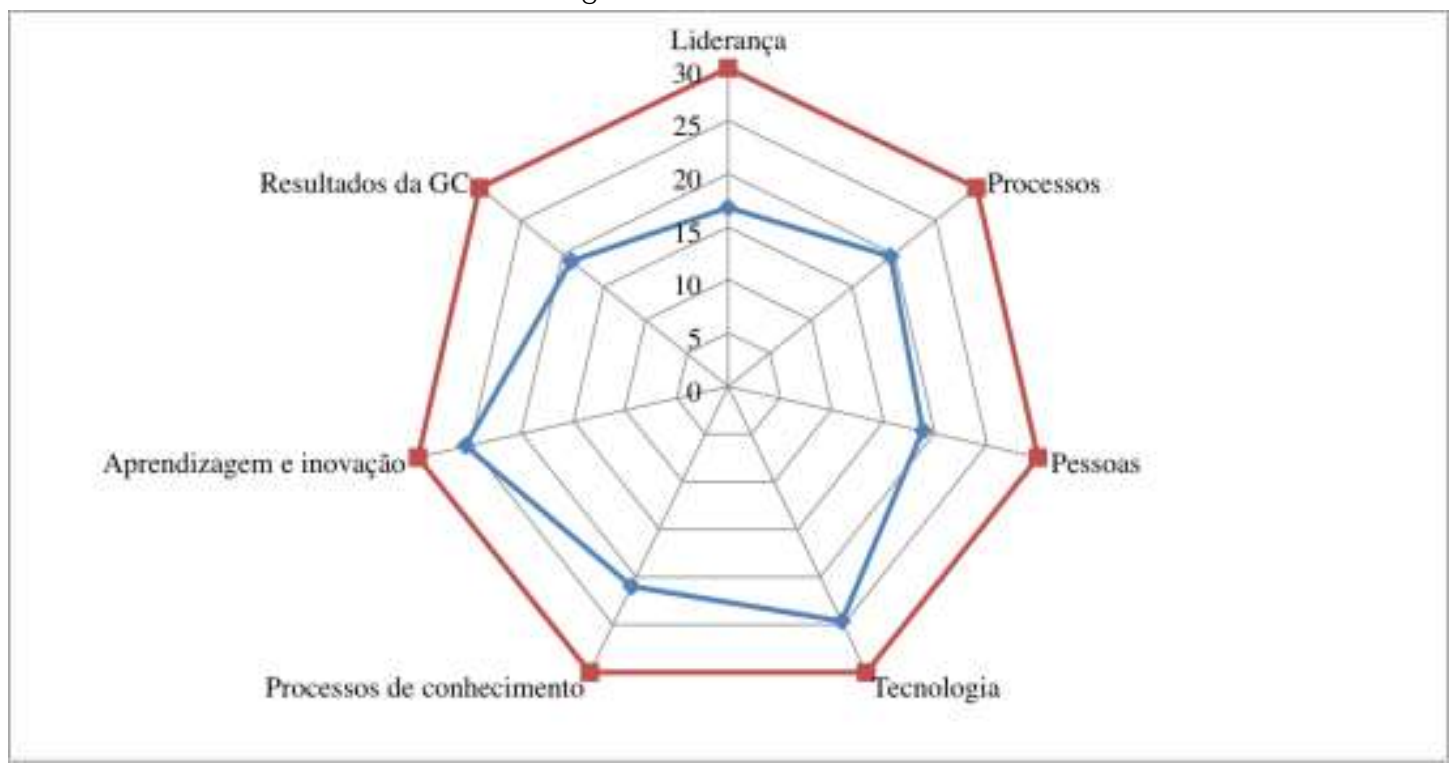

Fonte: Elaborado pelo autor (2018). 


\subsection{Instituto Comunitário Grande Florianópolis - ICOM}

Quadro 11 - Pontuação do ICOM

\begin{tabular}{|l|l|l|}
\hline$\#$ & Dimensão & Pontuação \\
\hline 1 & Liderança & 19,3 \\
\hline 2 & Processos & 21,1 \\
\hline 3 & Pessoas & 19,6 \\
\hline 4 & Tecnologia & 22,8 \\
\hline 5 & Processos de conhecimento & 19,3 \\
\hline 6 & Aprendizagem e inovação & 24,1 \\
\hline 7 & Resultados da GC & 18,6 \\
\hline \multicolumn{2}{|l|}{ Total } & $\mathbf{1 4 4 , 8}$ \\
\hline \multicolumn{2}{|l|}{ Terceiro nível identificado: expansão (126-146). } \\
\hline
\end{tabular}

Fonte: Elaborado pelo autor (2018).

Figura 7 - Gráfico do ICOM

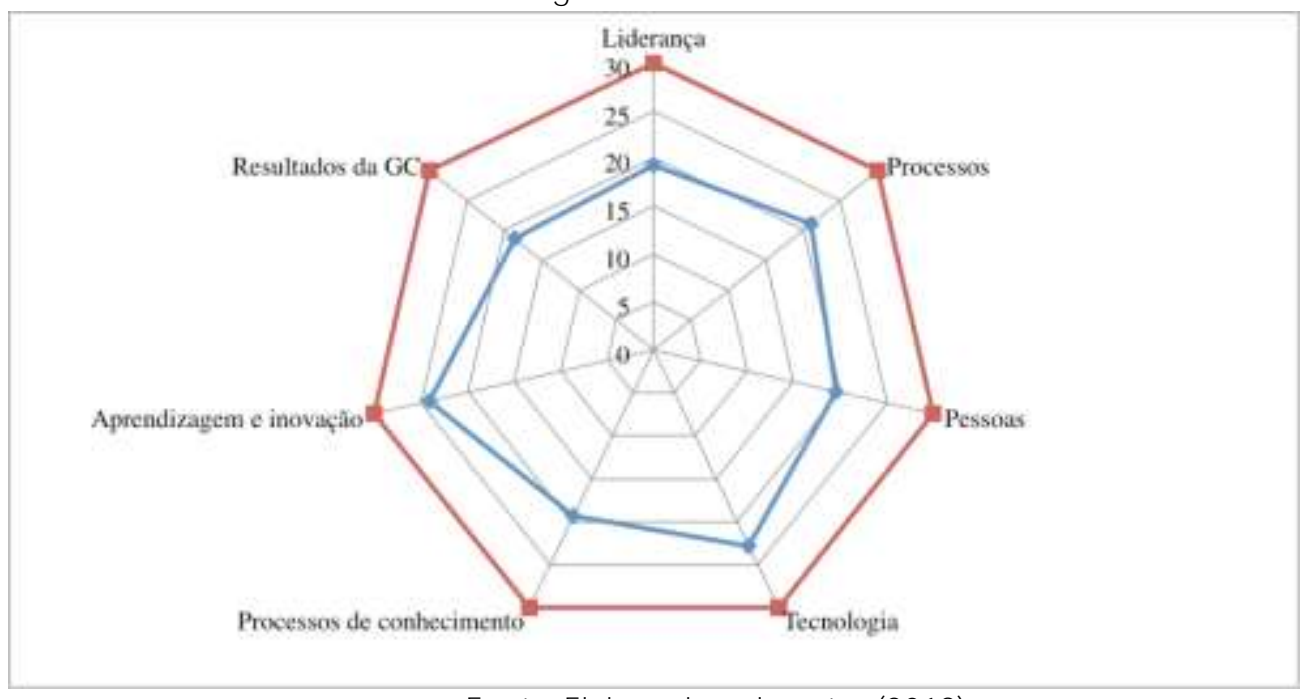

Fonte: Elaborado pelo autor (2018).

\subsection{Politize!}

Quadro 12 - Pontuação do Politize!

\begin{tabular}{|l|l|l|}
\hline$\#$ & Dimensão & Pontuação \\
\hline 1 & Liderança & 19,75 \\
\hline 2 & Processos & 22,125 \\
\hline 3 & Pessoas & 18,25 \\
\hline 4 & Tecnologia & 23,25 \\
\hline 5 & Processos de conhecimento & 22,5 \\
\hline 6 & Aprendizagem e inovação & 23,5 \\
\hline 7 & Resultados da GC & 17,375 \\
\hline \multicolumn{2}{|l|}{ Total } & $\mathbf{1 4 6 , 7 5}$ \\
\hline \multicolumn{2}{|l|}{ Quarto nível identificado: refinamento (147-188). } \\
\hline
\end{tabular}

Fonte: Elaborado pelo autor (2018). 
Figura 8 - Gráfico do Politize!

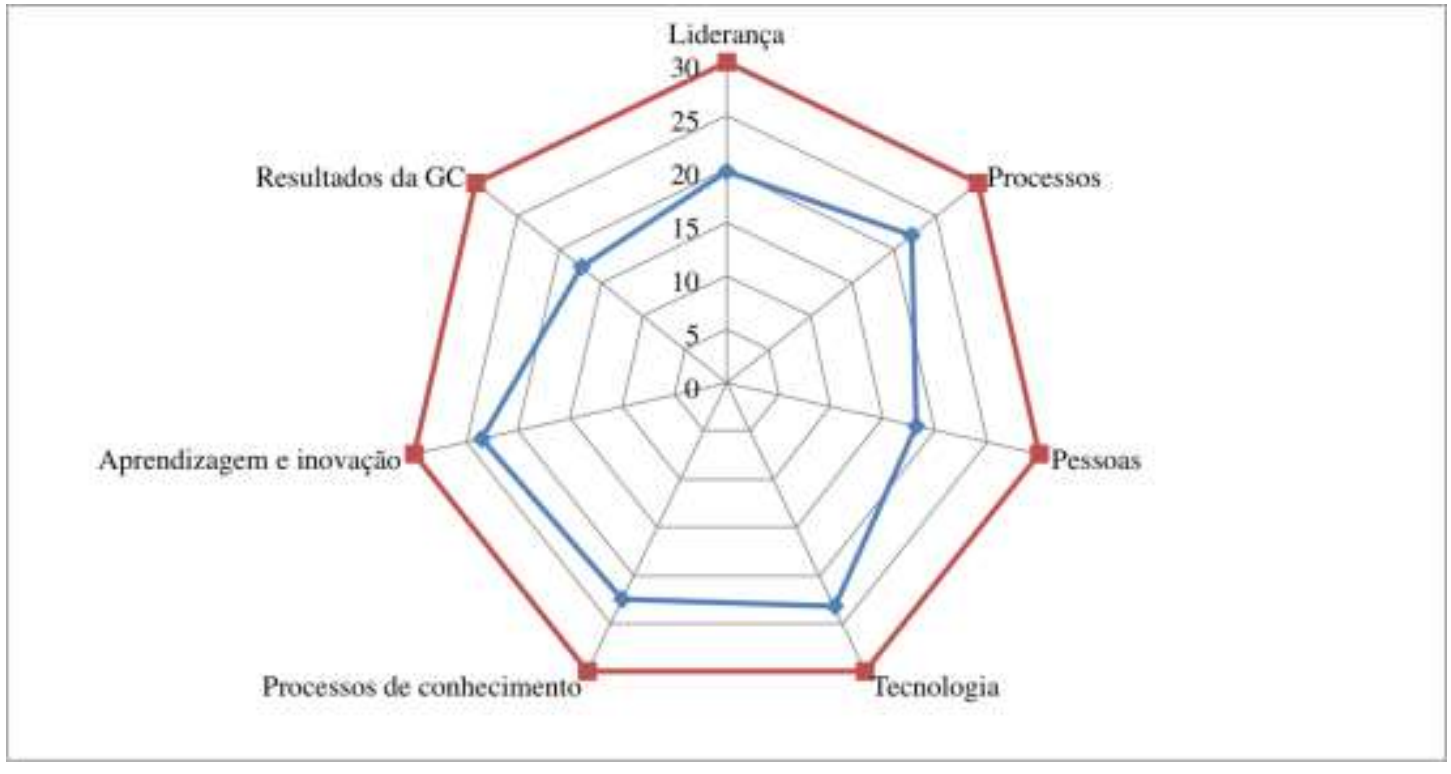

Fonte: Elaborado pelo autor (2018).

\subsection{Comparativo}

Quadro 13 - Comparativo das pontuações

\begin{tabular}{|l|l|l|l|l|l|}
\hline$\#$ & Categoria & ACBG & ICOM & Politize! & Máximo \\
\hline 1 & Liderança & 16,8 & 19,3 & 19,75 & 30 \\
\hline 2 & Processos & 19,6 & 21,1 & 22,125 & 30 \\
\hline 3 & Pessoas & 18,8 & 19,6 & 18,25 & 30 \\
\hline 4 & Tecnologia & 24,6 & 22,8 & 23,25 & 30 \\
\hline 5 & Processos de conhecimento & 21 & 19,3 & 22,5 & 30 \\
\hline 6 & Aprendizagem e inovação & 25,4 & 24,1 & 23,5 & 30 \\
\hline 7 & Resultados da GC & 19 & 18,6 & 17,375 & 30 \\
\hline & & $\mathbf{1 4 5 , 2}$ & $\mathbf{1 4 4 , 8}$ & $\mathbf{1 4 6 , 7 5}$ & $\mathbf{2 1 0}$ \\
\hline
\end{tabular}

Fonte: Elaborado pelo autor (2018). 
Figura 9 - Gráfico comparativo

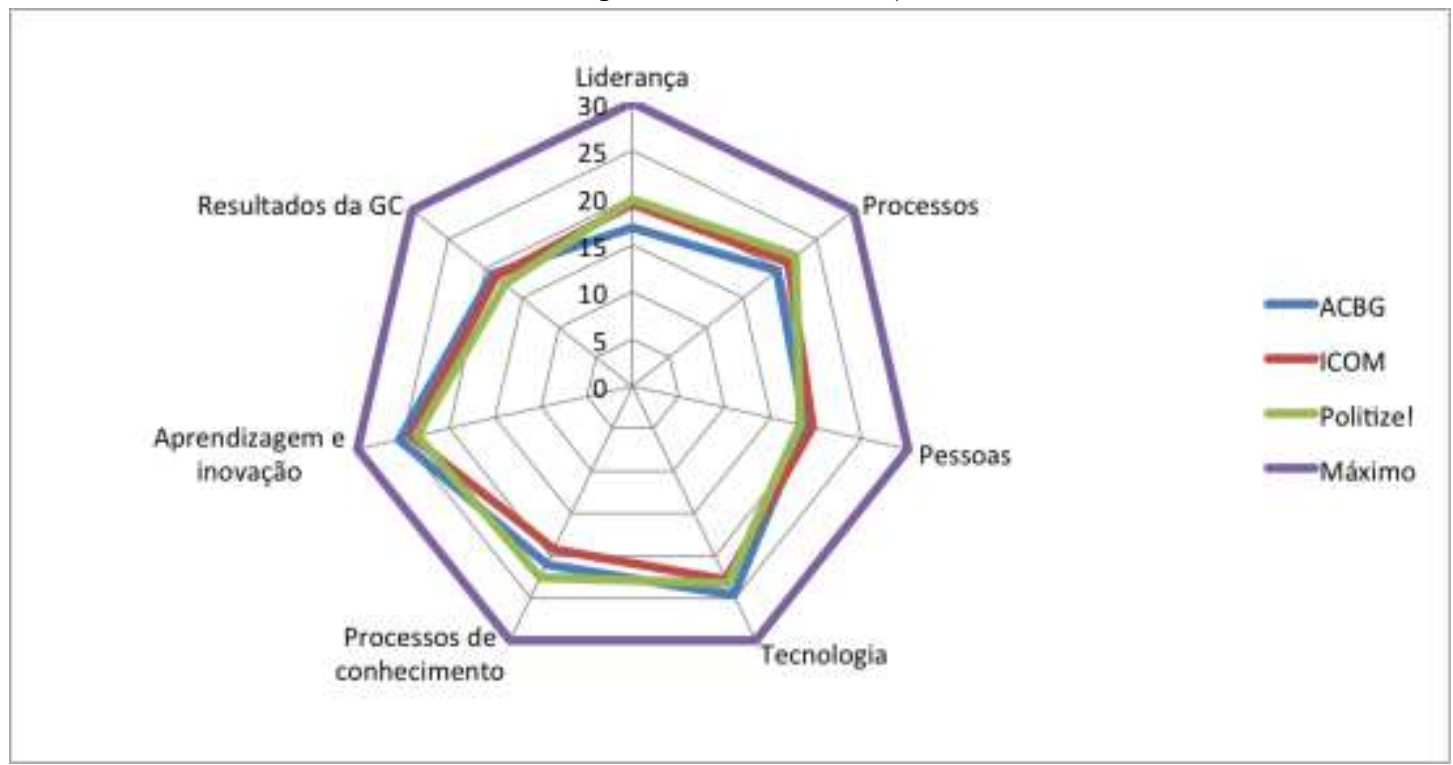

Fonte: Elaborado pelo autor (2018).

\section{DISCUSSÃO DOS RESULTADOS}

Antes de mais nada, é importante mencionar que, de acordo com as classificações propostas pelo método APO, as três organizações alcançaram pontuações que as colocam no nível de expansão, que é o terceiro nível da escala. Dito isso, vale pontuar a proximidade dos resultados do diagnóstico entre as três organizações, visto que a diferença entre a maior e a menor pontuação geral foi de apenas 1,95. Entre as pontuações de cada dimensão as diferenças também foram pequenas (Quadro 11). Tal cenário pode indicar, de algum modo, um padrão da percepção e prática da gestão do conhecimento no setor de forma mais ampla, visto que as três organizações, mesmo atuando em frentes diferentes, chegaram a resultados similares. Outro padrão que se fez notar foi a proximidade entre as dimensões com pontuações mais altas e mais baixas para cada uma das OSCs.

Quadro 14 - Pontuações mais altas e baixas por organização

\begin{tabular}{|c|c|c|}
\hline$\#$ & Pontuação mais baixa & Pontuação mais alta \\
\hline ACBG & Liderança $(16,8)$ & Aprendizagem e inovação $(25,4)$ \\
\hline ICOM & Resultados da GC $(18,6)$ & Aprendizagem e inovação $(24,1)$ \\
\hline Politize! & Resultados da GC $(17,375)$ & Aprendizagem e inovação $(23,5)$ \\
\hline
\end{tabular}

Fonte: Elaborado pelo autor (2018).

Embora a pontuação mais baixa da ACBG tenha sido na dimensão de liderança, o padrão indicado para o ICOM e Politize!, com a nota mais baixa em resultados da GC, deve ser salientado, visto que a ACBG também não pontuou muito mais.

As organizações demonstram compreender a importância da Gestão do Conhecimento, mas, como não realizam ações estruturadas de GC, não conseguem relacionar a causalidade de possíveis bons resultados.

A questão da liderança, além de ser a principal fraqueza na ACBG, também foi alvo de baixas pontuações nas outras duas organizações, deixando evidente que a presença de uma liderança que conduza a implementação e manutenção de um programa de Gestão do Conhecimento faria toda diferença.

Aproveitando a sinergia entre tais dimensões, vale mencionar o que fora observado para a dimensão de pessoas, que conecta diretamente o capital humano em consonância com o conhecimento. 0 fato é que, 
novamente, três pontuações muito parecidas - e apenas pouco maior que a metade da pontuação máxima possível - refletem a necessidade de um olhar mais acurado para a conexão dos colaboradores com a importância da Gestão do Conhecimento. No entanto, interpreta-se que isto está muito mais relacionado com as dimensões de processos (da organização como um todo) e processos do conhecimento. Afinal, cabe a organização, do ponto de vista estratégico, dar a base para que as pessoas se conectem a um modelo mental que valorize o conhecimento. 0 mesmo se articula com a liderança, que seria guardiã de tal modelo mental a ponto de facilitar sua perpetuação na equipe. A liderança já foi posta como um ponto oscilante nas organizações estudadas e com a questão dos processos não será diferente, com observaremos mais a frente.

Entre as pontuações mais altas, outro padrão. A dimensão de aprendizagem e inovação foi o destaque nas três organizações, o que pode indicar uma predisposição para implementação de um programa de Gestão do Conhecimento, visto que este envolve um caráter de inovação por si, bem como um foco na aprendizagem contínua. A necessidade de aprender e inovar constantemente no terceiro setor acaba se justificando pela complexidade dos problemas sociais, como fora apontado na introdução deste artigo. Visto que há espaço e vontade para inovação, a pergunta que fica provavelmente se relacione ao como inovar. Assim, temos uma dimensão muito associada à capacidade de liderança, que seria a figura simbólica capaz de criar um ambiente seguro para inovações, estimulando sua equipe a vivenciar este processo a despeito dos erros que possam cometer.

Conectado com a linha de aprendizagem e inovação temos a dimensão de tecnologia, que em segundo lugar foi a que apresentou as melhores pontuações para todas as organizações. Mas aqui faz-se uma crítica ao instrumento, tanto por parte do pesquisador como do que fora observado nas respostas dos participantes.

As assertivas postas nesta dimensão têm caráter muito básico. Considerando que tal método foi cunhado em 2009, praticamente 10 anos após o presente estudo, é de se compreender que algumas assertivas se tornaram reducionistas. A tecnologia vem avançando muito e tais pontuações altas infelizmente não representam um alto potencial tecnológico em tais organizações, muito menos no que se relaciona a implantar e monitorar um programa de Gestão do Conhecimento. Tais organizações sofrem muito com a disponibilidade de recursos para investimentos em tecnologias bem como carecem de competência técnica para um uso efetivo. Não somente esta dimensão, mas todo o método APO está passível a uma revisão e tal reflexão será melhor pontuada nas conclusões deste trabalho.

Por fim, as dimensões de processos e processos do conhecimento serão discutidas de forma conjunta por se entender que há uma relação direta entre elas. 0 fato é que o terceiro setor apresenta como um dos seus principais desafios ter uma gestão qualificada. Evidente que se trata de um conceito amplo, mas certamente em seu bojo entra a questão de papéis e processos bem definidos. Na prática, há uma grande dificuldade por parte das organizações do terceiro setor em mapear processos de modo a ter uma maior organização e eficiência de suas atividades. Majoritariamente, por falta de conhecimento do como fazer e também por falta de clareza dos resultados positivos que isso pode trazer, não se caracteriza como uma prioridade organizacional. No terceiro setor ainda se observa uma gestão muito tácita, se é que podemos chamar desta forma. Ou seja, muito está dentro dos líderes e pouco está externalizado e sistematizado para toda a equipe. Muitas vezes tais líderes têm um conhecimento extremamente valioso do ponto de vista empírico e relacionado à atividade fim, no entanto, há uma lacuna grande de conhecimentos de gestão que possa servir de base ao alcance da missão organizacional. Dado este cenário, fica evidente que ter processos de conhecimento bem definidos passa por um nível ainda mais profundo, visto que se espera que a organização já tenha um mapeamento de processos de forma geral e o siga em sua forma de executar as atividades.

\section{CONCLUSÃO}

Percebe-se que a Gestão do Conhecimento ainda é um desafio para as organizações estudadas. Paradoxalmente, entendem a importância em gerir conhecimento mas não priorizam tal atividade e, portanto, não se torna uma cultura totalmente integrada à estratégia da organização, o que reflete na ausência de 
processos de conhecimento bem estruturados. As organizações tendem a gerir conhecimento de forma intuitiva, dependendo majoritariamente da preocupação individual de cada colaborador em fazer tal gestão ou de um líder que trabalhe fortemente junto a cultura organizacional.

Reforçando o que fora apresentado inicialmente, o terceiro setor cresceu significativamente ao longo dos últimos anos, representando uma parcela considerável de pessoas empregadas e de formação do PIB brasileiro, no entanto, os desafios de gestão são inúmeros. Foi possível observar com esta pesquisa que gerir conhecimento não desperta uma urgência tão grande quanto gestão de voluntários ou captação de recursos, por exemplo. Uma pesquisa como essa pode ser considerada como um primeiro passo para uma reflexão organizacional rumo à implementação de um programa de Gestão do Conhecimento na organização. A partir de tal reflexão, espera-se que as organizações percebam que por meio da Gestão do Conhecimento muitos outros desafios podem ser enfrentados, visto que o conhecimento é a base de qualquer processo e se melhor gerido poderá trazer benefícios para os principais gargalos da organização.

Assim sendo, faz-se mister observar que a principal conclusão da pesquisa acerca de todas as dimensões apresentadas é que se não houver uma incorporação da Gestão do Conhecimento como parte inerente à estratégia da organização, torna-se insustentável dar vazão às necessidades de cada dimensão. Em outras palavras, todas as dimensões estão conectadas e o baixo desempenho em uma reflete diretamente nas outras. A exemplo disso temos a deficiência na dimensão liderança que reflete muito na dimensão pessoas. A deficiência na dimensão processos que reflete muito na dimensão processos de conhecimento. A falta de uma estratégia estabelecida para o conhecimento - e a consequente falta de processos para tal - que reflete diretamente na deficiência da dimensão dos resultados da GC. Em suma, as organizações estudadas precisam considerar uma reflexão estratégica, sobretudo, antes da tomada de decisão acerca de qualquer um dos achados da pesquisa.

Do ponto de vista acadêmico, espera-se que tal estudo sirva como inspiração para novas abordagens científicas sobre terceiro setor e Gestão do Conhecimento. Faz-se necessário caminhar para uma discussão mais ampla, tanto na expansão do arcabouço teórico desta temática como em sugestões práticas. Mais pesquisas que foquem na avaliação da Gestão do Conhecimento em OSCs seriam muito bem-vindas, assim se criaria uma amostra maior de organizações estudadas para possíveis comparações, levando a identificação de padrões e tendências.

Como principal limite da pesquisa confirmou-se a fragilidade do instrumento de coleta de dados utilizado para o dado contexto, levantado como hipótese inicialmente. Isso em função de dois fatores: 1) as assertivas não são sempre muito claras, não proporcionando uma fácil e rápida interpretação por parte do respondente, e; 2) as dimensões não contemplam aspectos fundamentais no terceiro setor, como captação de recursos, mobilização de voluntários e legitimação social, conhecimentos críticos para grande maioria das entidades. Além disso, por se tratar de um instrumento estabelecido no ano de 2009, sugere-se uma revisão de suas assertivas à luz das transformações que o ecossistema organizacional vem sofrendo desde então. Por essas razões é que se sugere que futuros estudos busquem instrumento de coleta alternativo para avaliação de maturidade em OSCs, podendo ter por base o aqui utilizado, bem como outros disponíveis na literatura, mas principalmente agregando elementos de extrema importância ao terceiro setor - não considerados nos instrumentos mais conhecidos, pois costumam ser focados na realidade do segundo setor - e adaptando sua linguagem de forma a estar adequada ao contexto.

\section{REFERÊNCIAS}

ANDRADE, Sebastião Carlos de Oliveira. Gestão competitiva e lucro social. Rio de J aneiro: IMAH, 2002.

ASIAN PRODUCTIVITY ORGANIZATION. Knowledge management: facilitator's guide. 2009. Disponível em: http://www.apo-tokyo.org/00e-books/IS-39_APO-KM-FG.htm. Acesso em:27 nov. 2016.

BRASIL. Código Civil, Lei 10.406, de 10 de janeiro de 2002. São Paulo: Revista dos Tribunais, 2002. 
BRASIL. Constituição da República Federativa do Brasil. 1988. Disponível em: https://go0.gl/HwJ $1 \mathrm{Q}$. Acesso em: 21 jul. 2017.

CAMARGO, Mariângela Franco de et al. Gestão do terceiro setor no Brasil. São Paulo: Futura, 2001.

CARDOSO, Ruth. Fortalecimento da sociedade civil. In: IOSCHPE, Evelyn Berg (org.). 3ㅇ Setor: desenvolvimento social sustentado. Rio de J aneiro: Paz e Terra, 1997. p. 7-12.

CHOY, Chong Siong; KUAN YEW, Wong; LIN, Binshan. Criteria for measuring KM performance outcomes in organisations. Industrial Management \& Data Systems, v. 106, n. 7, p. 917-936, 2006.

COMITÉ EUROPÉEN DE NORMALISATION. European Guide to good Practice in Knowledge Management Part 1: Knowledge Management Framework. Belgium: CWA, European Committee For Standardization, 2004.

ECONOMIST INTELLIGENCE UNIT. The Economist Intelligence Unit's Democracy Index. 2017. Disponível em: https://infographics.economist.com/2017/Democracylndex/. Acesso em: 18 ago. 2017.

FERNANDES, Rubem César. O que é o terceiro setor. In: IOSCHPE, Evelyn Berg. (org.). 3o Setor: desenvolvimento social sustentado. Rio de Janeiro: Paz e Terra, 2005. p. 25-33.

FISCHER, Rosa Maria; FALCONER, Andrés Pablo. Desafios da parceria governo e terceiro setor. Revista de administração, v. 33, n. 1, p. 12-19, 1998.

GOHN, Maria da Glória. Mídia terceiro setor e MST: impactos so bre o futuro das cidades e do campo. Cadernos de Pesquisa, n. 112, p. 213-213, 2001.

IBGE. Fundações privadas e associações sem fins lucrativos no Brasil. 2010. Disponível em:

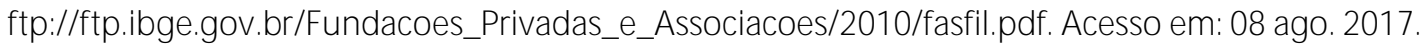

IPEA. Mapa de OSCs. Brasília: Ipea, 2018. Disponível em: https://mapaosc.ipea.gov.br/. Acesso em: 21 ago. 2017.

MADEIRA, Felícia Reicher; BIANCARDI, Miriam Ribeiro. 0 desafio das estatísticas do terceiro setor. São Paulo em Perspectiva, v. 17, n. 3-4, p. 177-184, 2003.

SALAMON, Lester M.; ANHEIER, Helmut K. The third world's third sector in comparative perspective. Baltimore:J ohns Hopkins University; Institute for Policy Studies, 1997.

MORESI, Eduardo Amadeu Dutra. Delineando o valor do sistema de informação de uma organização. Ciência da Informação, Brasília, v. 29, n. 1, p. 14-24, 2000.

NONAKA, Ikujiro; TAKEUCHI, Hirotaka. Criação do Conhecimento na Empresa: como as empresas geram a dinâmica da inovação. Rio de J aneiro: Campus,1997

ONU. Handbook on Non-Profit Institutions in the System of National Accounts. 2003. Disponível em: https://goo.gl/UPcQ71. Acesso em: 12 ago. 2017.

STAIR, Ralph. M. Princípios de sistemas de informação: uma abordagem gerencial. Rio de J aneiro: LTCLivros Técnicos e Científicos, 1998.

TENÓRIO, Fernando G. Gestão de ONGs: principais funções gerenciais. Rio de Janeiro: Editora FGV, 2001. TOZZI, J osé Alberto. S.0.S da ONG: guia de gestão para organizações do Terceiro Setor, São Paulo: Gente, 2015. 
VENZIN, Markus; VON KROGH, Georg; ROOS, J ohan. Future research into knowledge management. In: VON KROGH, Markus et al. (org.). Knowing in firms: Understanding, managing and measuring knowledge, 1998. p. 26-66.

VESTAL, Wesley. Measuring knowledge management. USA: American Productivity \& Quality Center, 2002. ZAYAS, Emilio López-Barajas. 0 paradigma da educação continuada. Porto Alegre: Penso Editora, 2009. 